\title{
Armas de metal en el Perú prehispánico
}

\author{
Carmen Pérez Maestro *
}

\begin{abstract}
RESUMEN ABSTRACT
A través del análisis del significado de la guerra en los Andes, de la tecnología con que las armas de metal fueron fabricadas, así como de la evolución de las mismas a través de los diferentes horizorites culturales,

hemos tratado de recuperar todos aquellos ejemplos de objetos de metal, hayan cumplido una función utilitaria o

ritual, para llegar a tener asi una amplia visión de la significación de las armas de metal en el Perú Prehispánico.

\section{PALABRAS CLAVE} Arqueología, etnohistoria, iconografía, culturas prehispánicas, guerra ritual, guerra secular, tecnología, simbolismo, armas ofensivas y defensivas.

In this article, we describe all known examples of Andean metal weapons, regardless of their functionality, in order to gain a wide view of their meaning in Prehispanic Peru. For this purpose, we analyze the meaning of war in Andean Area, the technology of elaboration of the weapons and their evolution throught different cultural periods.

\section{KEY WORDS}

Archaeology, etnohistory, iconography, prehispanic cultures, ritual war, secular war, technology, simbolism, offensive and defensive weapons.
\end{abstract}

* Alumna de doctorado del Departamento de Prehistoria (UNED). Valle Inclán $1,2 .^{\circ} \mathrm{B}$. 28044 Madrid. E-mail jlperez@ recol.es. 


\section{INTRODUCCIÓN}

A pesar de la temprana aparición de la actividad metalúrgica en el área Central Andina ( \pm 800 a.C.), el metal no fue elegido como materia prima principal para la elaboración de armas. Quizás su avanzada tecnología lítica les permitió la utilización de la piedra para la fabricación de cualquier tipo de instrumentos, incluyendo las armas, hasta la llegada de los españoles. Una concepción de los conflictos intergrupales diferente a la europea, nos les obligó a revolucionar con el uso del metal, la tecnología de la guerra. Si sumamos esto a que la mayoría de las armas de metal proceden de contextos funerarios, que han sido masivamente saqueados en Perú, la muestra se reduce a unos pocos objetos. Sea por una u otra causa, las sociedades andinas nos dejaron muy pocos ejemplos de armas de metal en los contextos arqueológicos que hoy analizamos.

\section{LAS FUENTES DE ESTUDIO}

Los objetos de metal enseguida llamaron la atención de los conquistadores y, aunque como ya veremos más adelante "no era oro todo lo que relucía", éstos fueron sistemáticamente recogidos para ser fundidos y enviados a España en barras de plata y tejos de oro. La extirpación de idolatrías supuso también la destrucción masiva de muchas construcciones y objetos prehispánicos considerados paganos por la nueva religión llegada al Perú.

Las piezas de textil, cerámica, y sobre todo metal, son muy apreciadas por los coleccionistas de todo el mundo. La venta o tenencia del objeto más bello ha llevado a vendedores y coleccionistas privados a arreglar y componer las piezas metálicas a su gusto. «De esta manera encontramos en colecciones privadas importantes piezas de metal arregladas según el gusto del conservador, con láminas o piedras de colores que no les corresponde, lo que varía totalmente el significado real de la pieza y dificulta más un verdadero estudio interpretativo. Unas veces se añaden elementos decorativos a las piezas, otras se quitan y al final la pieza está tan mutilada que resulta prácticamente una caricatura de su estado original» (Carcedo, en prensa). Tenemos la suerte, sin embargo, de que en los últimos años se han desarrollado serios proyectos de investigación arqueológica, gracias a los cuales se ha podido recuperar una valiosa información respecto a las manifestaciones culturales relacionadas con la guerra o con la metalurgia en el mundo Andino. Por esto la fuente arqueológica se torna fundamental para el estudio contextual de dichos objetos. 
Las diversas manifestaciones culturales de las sociedades andinas fueron representadas en textiles, cerámica o metal por ellos mismos. La fuente iconográfica nos permite en muchas ocasiones confrontar las hipótesis que formulamos a través de los datos arqueológicos y etnohistóricos.

Son datos etnohistóricos aquellas descripciones iniciales de las sociedades andinas procedente de los soldados, los funcionarios o los historiadores españoles que llegaron a estas tierras. Las primeras fuentes que se ocupan del Perú Antiguo son los documentos españoles del siglo XVI, referidos algunos de ellos a describir el Imperio de los Incas aún cuando la mayoría estaban destinados a contar y registrar la vida y conflictos de los conquistadores. Después del siglo XVI se escribieron una serie de documentos que si bien ya estaban alejados del Imperio inca, contienen testimonios de su cultura. Destacan así los que se hicieron a raíz de la extirpación de idolatrías, que describen sistemas de cultos y creencias que de otro modo se hubieran perdido. Hemos de tener en cuenta sin embargo que la mentalidad de los cronistas no estaba preparada para entender etnografías tan lejanas a la suya, lo que provocó en muchas ocasiones el mal entendimiento de aquello que estaban observando. Esto nos obliga a tratar con mucho cuidado estos datos, que necesariamente han de ser complementados con los arqueológicos.

Tecnologías en la fabricación y tratamiento de los objetos de metal, se han conservado desde épocas prehispánicas en muchas comunidades andinas. Existen además actividades rituales relacionadas con la guerra, que se continúan realizando en áreas restringidas del Perú y Bolivia. Los datos etnográficos por tanto nos van a ayudar también a una mejor comprensión de las sociedades pasadas.

\section{LA GUERRA EN LOS ANDES}

Cualquier rápida interpretación que se dé a un instrumento o una construcción arquitectónica puede resultar equivocada si no se cuenta con informaciones complementarias que la corroboren. La abundancia de representaciones de armas y guerreros en los restos culturales preincaicos e incaicos parecería indicar que estos pueblos fueron bélicos, sin embargo, la dependencia de éstas al arte militar es hasta ahora bastante dudosa.

El concepto de «guerra» en el mundo Andino ha sido analizado mayormente desde el punto de vista occidental, por esto tenemos una visión equivocada de lo que significó en las culturas prehispánicas andinas. La 
conceptualización de la guerra en Los Andes ha sido muchas veces obstaculizada por la confusión entre la "guerra ritual» y "guerra secular».

Los testimonios de la presencia de supuestas actividades guerreras se prestan a dudas. "En ciertos lugares las poblaciones eran rodeadas de empalizadas y también con murallas, no con el fin de defenderse del ataque armado de otros hombres, sino de las fieras que pudieran penetrar en ellas para causar destrozos y muerte, o para impedir la intrusión de huéspedes no deseados. Algo de esto parece, por ejemplo, vislumbrarse en la ciudadela de Piquillacta, cerca del $\mathrm{Cuzco}$, con un trazo expresamente laberíntico de sus calles, o en la ciudad de Chan Chan, donde en varios de sus recintos sólo podía penetrarse por unas rampas desde el tope de sus anchos muros que eran de gran altura, para que tuviera el visitante que exponerse a la vista de todos" (Cisneros 1980:19).

Los recintos defensivos que encontramos, sobre todo en la Costa Norte, como por ejemplo la fortaleza de Paramonga, parecen haber servido de escenarios a combates rituales destinados a obtener futuras víctimas para sacrificios. En estas fortalezas no se encuentran ni puntas de lanzas ni proyectiles de hondas, sólo están presentes cuchillos de pizarra pulida.

Estos recintos no parecen proteger territorios, sino solamente construcciones de carácter ceremonial en cuyo interior aparecen antaras (flautas de pan) y restos de vasijas recipientes de chicha (bebida de maíz). "Todo ello hace pensar que las supuestas fortalezas de la Costa Norte fueron construidas en las fronteras entre las comunidades para servir de escenario a los combates rituales" (Makowski 1999:70).

Los sistemas ecológicos de la desértica vertiente occidental de los Andes Centrales, frágiles pero altamente productivos, crearon condiciones para la temprana aparición de conflictos por el acceso al agua y los recursos alimenticios. Durante el tercer y el segundo milenio a. C., la densidad de población aumientó considerablemente, lo que provocó la presión demográfica en las cuencas fértiles. Esta situación provocaría conflictos entre las comunidades que cohabitaban en un mismo valle. La existencia de "ataques organizados por parte de un grupo social contra otro en el intento de fomentar los intereses de un grupo a expensas del otro, mediante la destrucción premeditada de vidas y bienes» (Hoebel 1961:553), serían por lo tanto lógicos en estas áreas de recursos tan limitados.

Algunos autores como Topic (1997), niegan la existencia de una guerra territorial basándose en la pervivencia actual del llamado Tinku o batalla ritual en comunidades serranas de Perú y Bolivia, pero la oposición entre combate ritual y guerra profana no es compatible con la cosmovisión andina. 
La ritualización de los comportamientos bélicos es común en todas las sociedades complejas preindustriales, lo que no excluye por tanto ninguna de las dos.

Tanto las armas ofensivas como las defensivas que conforman el bagaje cultural andino, demuestran que si sirvieron para ser utilizadas en combates, al menos del tipo cuerpo a cuerpo. El metal no supuso una revolución en la guerra como sucedió en el Viejo Mundo, pero no podemos olvidar las pesadas porras con cabeza de cobre o bronce vaciadas o las puntas con mango largo recubiertas de metal que fueron generalizadas por las culturas Moche o Recuay, las cuales «tuvieron que ser muy respetadas por su mortífera eficiencia» (Makowski 1999:66).

Por otro lado, muchos de los objetos que consideramos como armas, por su tamaño o por la fuerte inversión de trabajo que supuso su elaboración, no parecen haber resultado operativos para un combate. La colocación de dichos objetos en contextos funerarios nos estaría indicando que fueron fabricadas no con un fin utilitario, sino como meros indicativos de estatus.

\section{TECNOLOGÍA Y SIMIBOLISMO DEL METAL}

Todos los artículos de una cultura material y más aun cuando se trata de los metales, son el resultado de la explotación de recursos materiales presentes en el medio ambiente y de una conversión de dichos materiales en objetos. Lo que constituye un "sistema tecnológico" (Letchman 1997:154) es la selección de las materias primas, su procesamiento y, a través de la manipulación de sus propiedades, plasticidad, dureza o resistencia, su transformación en objetos culturales.

El Área Central Andina es considerada actualmente como la cuna del desarrollo de la metalurgia extractiva y de la orfebrería americana.

En un lugar llamado Cerro Barranco Colorado en la costa norte de Perú se encontró una mina prehispánica que nos da idea de cómo pudo ser el proceso extractivo de los minerales. Así es descrita por su descubridor": los antiguos mineros comenzando por la cima descendieron gradualmente hasta el centro de la montaña. Así aunque la abertura de la cima tenía una trinchera de menos de $1.5 \mathrm{~m}$ de ancho, se extendía casi $100 \mathrm{mts}$. hacia abajo de la ladera. La mina tenía por lo menos $40 \mathrm{mts}$. de profundidad y se ensanchaba por dentro hasta 8 o $9 \mathrm{mts}$., a tan sólo 3 o $4 \mathrm{mts}$. de la entrada, a partir de esta especie de cámara subterránea se descendía a un pozo vertical con estacas de madera y escalones excavados en la 
pared de mismo» (Carcedo 1999:52). Los instrumentos utilizados para la extracción del mineral serian fundamentalmente martillos y picos de piedra. En el desierto de Atacama al norte de Chile se descubrió de manera fortuita la momia del «hombre de cobre» (Bennet y Bird 1960) perteneciente a un minero prehistórico que portaba su instrumental de trabajo, consistente en cuatro martillos, azadón con hoja de piedra, azadón de madera, dos palitos de madera, una bolsa de cuero de llama, cuatro cestos y correa de cuero.

Los metales utilizados en los Andes Centrales fueron el oro, la plata, el cobre, el estaño y el plomo, tanto en estado nativo como obtenidos metalúrgicamente, y aleaciones intencionales comunes fueron cobre-plata, cobre-oro (tumbaga), cobre-arsénico (bronce arsenical), cobre-estaño (bronce estañifero) y cobre-oro-plata.

El cobre se fundía en hornos excavados en la arena, revestidos de gruesas capas de arcilla. El resultado era una cámara más o menos circular. En la parte superior de la bóveda era modelado un canal tubular lateral y otro central de forma cuadrangular a modo de chimenea (Makowski 1996).

Junto a los hornos aparecen toberas de cerámica o caña para soplar o inyectar aire en el horno. El metal que se obtenía de la fundición no corre a la parte inferior del horno formando un lingote, sino «prills o perlas, gotas de metal atrapadas en la escoria" (Carcedo 1999:16).

Según nos informan las crónicas, existía otro tipo de horno denominado huaira, realizado de barro, y de forma troncocónica con orificios redondos repartidos con uniformidad. En su pie se recogía el metal fundido y la escoria. Estas se colocaban en las partes altas de los cerros donde el viento actuaba como fuelle. El método de fundición preferido era el vaciado. Se utilizaban moldes abiertos o moldes de dos piezas para las herramientas como hachas, buriles, azadas o mazas hechas con cobre y sus aleaciones. La técnica de cera perdida era rara en Perú, sin embargo, era conocida por los herreros Moche y se utilizó para hacer las empuñaduras de los bastones y los adornos de cobre en los siglos previos a la conquista Inca.

Los metalurgos prehispánicos manifestaron una clara preferencia por dar forma a los objetos con la técnica del martillado. Las láminas obtenidas, se recortaban, se doblaban o se enrollaban según fuese necesario y se enmoldaban para producir objetos idénticos. Por último se repujaba, grababa o dibujaba la superficie para decorar. El cronista Garcilaso de la Vega describe de la siguiente manera como trabajaban los metalurgos del Cuzco: «Servianse para yunque de unas piedras durísimas de color verde y amarillo; aplanaban y alisaban unas con otras; tenánlas en gran estima por que eran muy raras...son de forma de dado, las esquinas muertas; 
unos son grandes, cuanto pueden abarcar con la mano para los golpes mayores; otros hay medianos y otros chicos y otros perlongados, para martillar en cóncavo; traen aquellos sus martillos en la mano para golpear como si fueran guijarros» (Lothrop 1978:530)

Los artesanos andinos además fueron expertos en "colorear» el metal, bien depositando una capa de oro o plata sobre la superficie, bien «mediante el tratamiento químico de la superficie de la aleación que contiene plata u oro, para eliminar de ella ciertos componentes no deseados, como el cobre, con el fin de dejar in situ el elemento o los elementos que confieren el color deseado al superficie, como la plata y el oro" (Carcedo 1999:22). Los objetos, por tanto, pueden tener un color en la superficie y otro totalmente distinto debajo. El oro y la plata, o más bien el color oro y el color plata, encerraban en sí un alto valor simbólico, eran los colores más apreciados dentro del espectro metalúrgico. Este fue el motivo por el que los orfebres y metalurgistas fueron auténticos maestros en otorgar color a las superficies metálicas por medio de las aleaciones y del recubrimiento de las piezas.

El metal entre los indígenas, no fue utilizado por su carácter funcional o por una manifestación de riqueza, sino por su simbolismo inherente. Por el hecho de proceder de la Pachamama (madre tierra) ya era considerado como sagrado. En diferentes minas y centros de fundición prehispánicos se han encontrado ofrendas rituales; en las minas, de conchas de Spondylus (molusco bivalvo usado en ofrendas y enterramientos durante toda la prehistoria andina) y en los centros de fundición, huesos de llama, fetos de camélidos, restos de comida y cerámica, "posiblemente dedicados a un dios o diosa relacionado con la actividad metalúrgica» (Carcedo 1999:5).

El metal fue además un medio para mostrar el contenido o mensaje del estatus y reforzar el poder político. El cobre y sus aleaciones constituyen la materia prima preferida para la indumentaria de culto y los símbolos de poder. Por otro lado, gran parte si no la totalidad de los artefactos utilitarios de metal, usados durante la vida como armas, utensilios, adornos y parafernalia de culto, terminaba en el interior de las cámaras funerarias junto a aquellos objetos que fueron fabricados expresamente para cumplir la función de ofrenda funeraria.

\section{LOS OBJETOS}

Las armas ofensivas: La porra, maza o rompecabezas es el arma que posee una mayor tradición cultural dentro de todos los tipos clasificados. Se trata de volúmenes con un orificio circular en el centro para ser 
enmangados. Las hay de muy diferentes formas, pero en su mayoría adoptan la estrellada. Hay magníficos ejemplos de las mismas realizadas en piedra desde el segundo milenio a.C. y con este material se siguieron fabricando hasta la llegada de los españoles. A fines del Formativo se realizan ya en metal mediante la técnica del vaciado y en cobre aleado con estaño o arsénico.

El tumi ha sido uno de los elementos de la cultura material que más aparece representado en la iconografía textil, lítica y cerámica. Es un objeto de metal constituido por un brazo vertical que termina en forma de media luna. Gran parte de los tumis han sido considerados como cuchillos ceremoniales, puesto que fueron utilizados supuestamente para el sacrificio de personas y animales. Debieron cumplir de todas maneras una función momentánea, puesto que por su tamaño y peso no pudieron haber sido utilizados habitualmente en un combate. La inversión de trabajo en la fabricación de los mismos y los hallazgos de estos tipos de tumis en contextos funerarios únicamente de personajes importantes, nos hace suponer que constituyeron un símbolo de poder de la persona que los poseía. Los tumis llevan en la parte superior representaciones de figuras humanas mitológicas (Sicán) o animales, generalmente cuadrúpedos, bien su cabeza, bien el animal completo (Inca).

Los cronistas describieron aquellos que ellos vieron de época Inca como un cuchillo de cobre o bronce sin mango con forma de hacha. Sin embargo, encontramos que el tumi fue realizado con formas variadas en las diferentes sociedades prehispánicas.

La mayoría de los tumis que han llegado hasta nosotros están fuera de todo contexto arqueológico, ya que por su belleza han sido considerados objetos muy preciados por el traficante de piezas arqueológicas; así pues sólo tenemos algunos ejemplos encontrados en contextos funerarios que nunca han sido alterados. Las tumbas de las culturas Moche, Sicán, e Inca son las que más objetos de este tipo nos han proporcionado, porque es en estas culturas donde más se han centrado las investigaciones en los últimos años. El hacha es otra de las formas típicas que desde el Intermedio Temprano aparece realizada en metal y que fue adoptando diversas morfologías a través del tiempo. Se considera hacha a todo objeto conformado por un extremo en forma de cuchilla y el otro con un apéndice para ser ésta amarrada a un palo de madera.

Armas defensivas: Consideramos como armas defensivas los cascos, los escudos y vestimentas protectoras. Fueron realizados de metal y madera, algodón, lana o plumas. Encontramos algunos ejemplos de protectores coxales de metal en la cultura Moche, sin embargo, nos parece que 
éstos sólo fueron utilizados como indumentaria en actividades rituales puesto que son de gran tamaño y peso. En diferentes contextos funerarios se han encontrado individuos con placas de metal que recubren su pecho y que podrian haber sido parte de una indumentaria protectora (Fig.1).

Los moche se protegían la cabeza con cascos cónicos realizados mediante un armazón de cañitas acolchado con algodón y recubiertos con una tela. Los escudos eran cuadrangulares o redondos y de madera con decoración incisa y pintada, y las camisas y faldellines de los combatientes iban reforzados con gruesas guatas de algodón (Cisneros 1980).

Los cascos Incas eran de madera en forma de cono que podían ir protegidos con anillos de metal. Los escudos también eran de madera forrados con cuero, vistosamente pintados o adornados con plumas y a veces con planchetas de cobre y plata. En ocasiones el guerrero Inca llevaba una vestidura denominada «escaupil» de fuerte tela acolchada de algodón o hecha de varias mantas de este mismo material pero superpuestas.

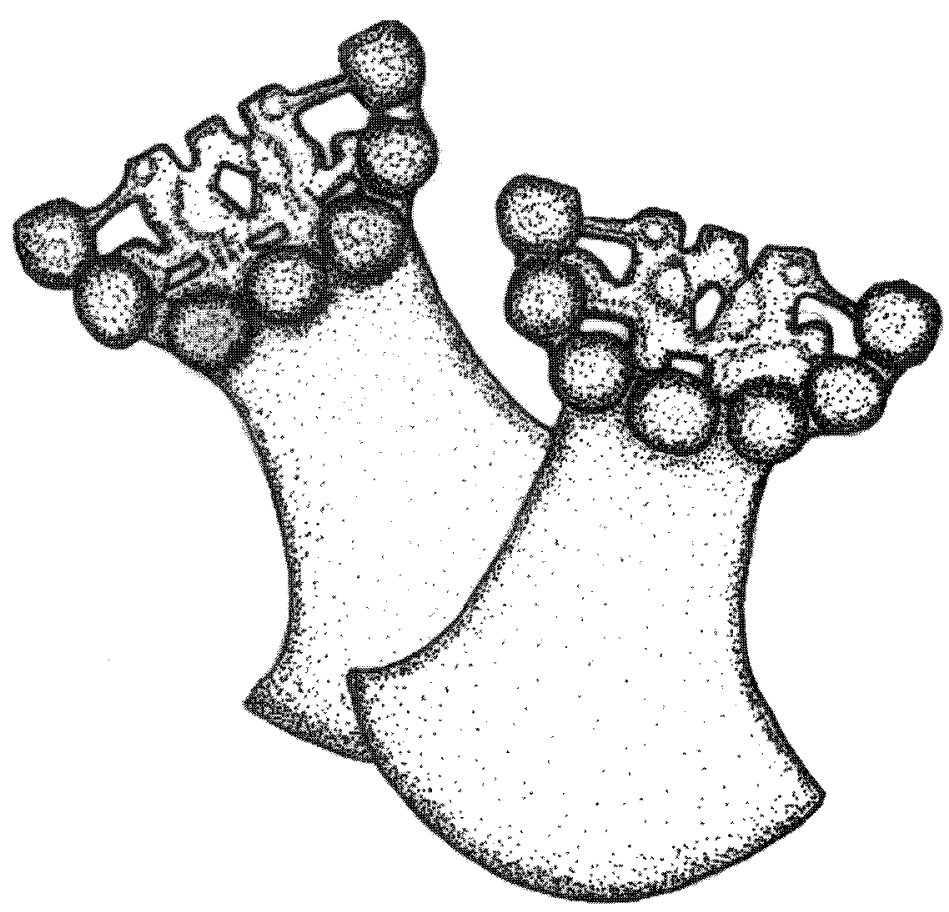

Fig. 1. Protectores coxales de cobre encontrados en una tumba Sipán $(22.5 \times 14 \mathrm{~cm}$.$) .$ 


\section{LAS ARMAS DE METAL EN LOS DIFERENTES HORIZONTES CULTURALES:}

No se han hallado armas de metal creadas por sociedades anteriores al siglo III a.C. A pesar de que encontramos representaciones de porras y cuchillos en la iconografía de los objetos del periodo formativo, no tenemos la certeza de si éstas fueron de piedra o de metal. Sin embargo, la presencia de gran cantidad de cuchillos de obsidiana, boleadoras y porras o macanas de piedra y puntas de pizarra pulida frente a la ausencia de cualquiera de estos en metal, confirma la no utilización del mismo para su fabricación.

Es a finales del Período Formativo u Horizonte Antiguo cuando el metal comienza a utilizarse para la elaboración de armas.

La cultura Vicús, que se desarrolló en los alrededores de Piura en la costa Norte de Perú, fue definida a partir de objetos procedentes de saqueos de tumbas, fundamentalmente objetos de cerámica y de metal. Las piezas más numerosas son las porras o mazas realizadas en cobre mediante la técnica del vaciado. Son estrelladas, hechas de planchas planas, dentadas sobre las que a veces aparecen motivos incisos. (Fig 2).

Es en el Período Intermedio Temprano donde empezamos a encontrar amplias muestras del uso del metal para la fabricación de armas. La cultura Moche se desarrolló entre los valles de Trujillo y Lambayeque, y se extendió por toda la costa Norte. Las armas son encontradas en contextos funerarios y asociadas a enterramientos de guerreros y altos dignatarios. "Los objetos de metal, ...indicaban una posición elevada de los periodos más tempranos de los moche y continuaron siendo propiedad exclusiva de la élite.» (Alva 1993:19).

La cerámica producida por los artesanos moche nos muestra en su decoración pintada numerosos tipos de escenas en las que se nos dan a conocer aspectos de su cultura material, ya que los individuos aparecen representados con innumerables atributos, como por ejemplo las armas. Hablamos de una cerámica que en su mayoría procede de colecciones particulares y que por tanto no tienen contexto arqueológico y en su minoría de vasijas encontradas en contextos funerarios cerrados de tumbas generalmente de altos mandatarios de la sociedad moche. No es por tanto una cerámica del pueblo, lo que nos está indicando probablemente que los temas que se representan tienen que ver con la elite y con mitos. Para el tema que nos ocupa debemos fijarnos básicamente en las escenas de combate y caza. En los desfiles de guerreros moche, los vemos portando armas de combate: estólicas, porras, dardos, cuchillos o tumis sobre el 


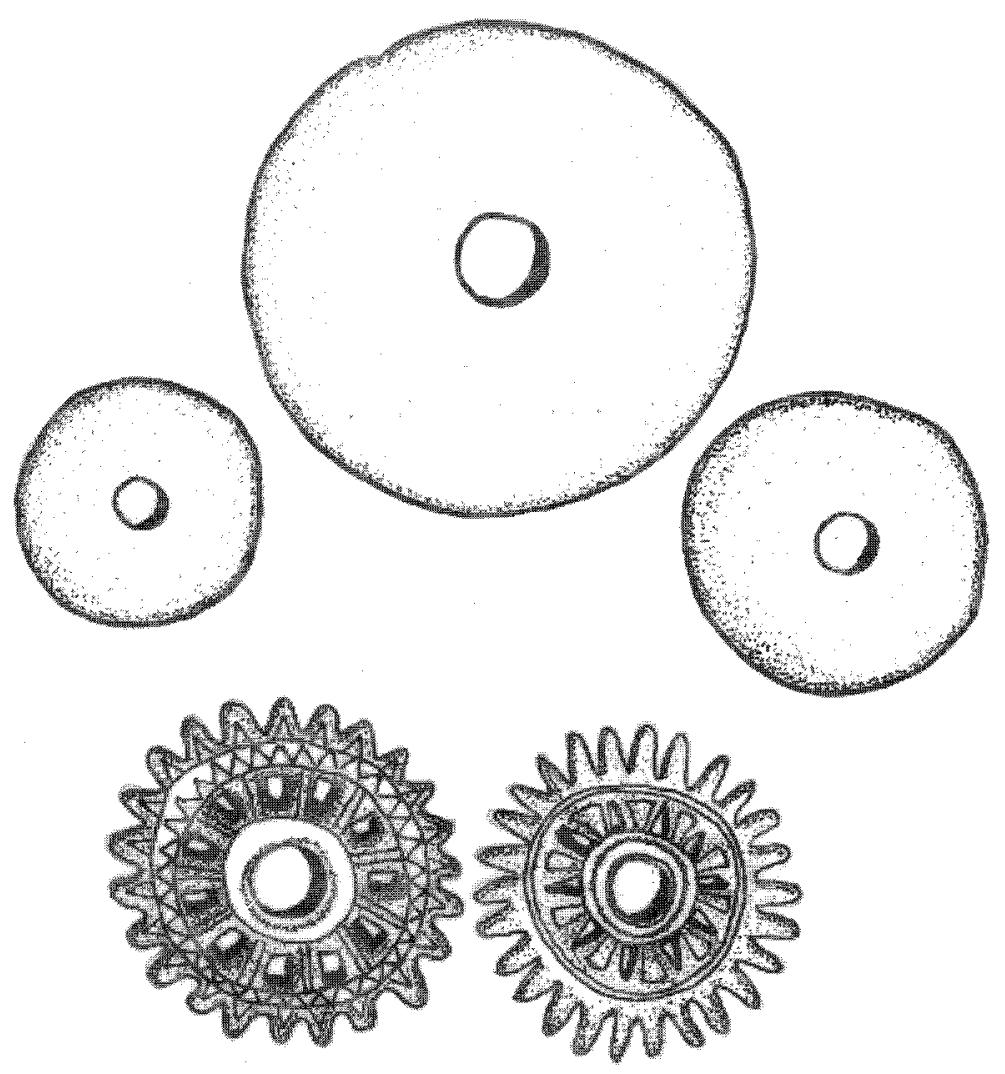

Fig. 2. Mazas circulares planas y porras ornamentales de cobre con diseños geométricos (de 6 a $8 \mathrm{~cm}$.).

tocado o colgados del cinturón. Van protegidos con escudos, sofisticados cascos, orejeras y chalchacas o sonajeros.

Existen otros objetos suntuarios que acompañan al difunto que representan guerreros. «El par de orejeras más asombroso es aquel que representa a los jefes guerreros...el guerrero tenia el tamaño del dedo pulgar de una mano y sostenía vigorosamente un mazo de guerra con en puño cerrado...Este mazo es una miniatura perfecta de esta antigua arma militar. Pequeñas sonajas en forma de luna creciente cuelgan de su cinturón. En su muñeca hay un escudo circular $¥$ en su cabeza tiene un complicado tocado con una gran luna creciente (Alva 1993:84).

El arma ofensiva más importante que todo guerrero de la cultura Moche llevaba a la batalla era la pesada porra que iba provista de un mango anu- 
lar. Estas porras, mazas o macanas que aparecen profusamente representadas en la iconografía moche, fueron realizadas de cobre y mediante la técnica del vaciado fundamentalmente. Las hay de muy diferentes formas, cónicas, circulares, estrelladas con seis o más puntas, pero con tamaños más o menos estándares de aproximadamente $10 \mathrm{cms}$. Algunas de ellas poseen decoración incisa mediante un cincel. (Fig. 3). En segundo lugar encontramos los tumis de cobre, oro y plata. Los de cobre están realizados mediante la técnica de la cera perdida y en la parte superior de los mismos aparecen representaciones de escenas de actividades humanas (Fig. 4); los de oro y plata están realizados mediante el martillado y recortado de una placa de metal y algunos pueden tener complejos dibujos cincelados que representen deidades con caracteres antropomorfos. El peso, el gran esfuerzo en la elaboración y la poca resistencia de las láminas de oro o plata hace suponer que los tumis sólo cumplieron una función ritual destinadas a conformar parte del ajuar. En la tumba del señor de Sipán, Donnan encontró dos tumis en el pecho del difunto, uno de oro y otro de plata. La parte superior de los mismos estaba perforada y tenían un cordón formando un lazo probablemente para ser colgados. En la iconografía observamos como los guerreros portan un tumi colgado de su cinturón. Muelle propone que en un principio estos tumis eran colocados

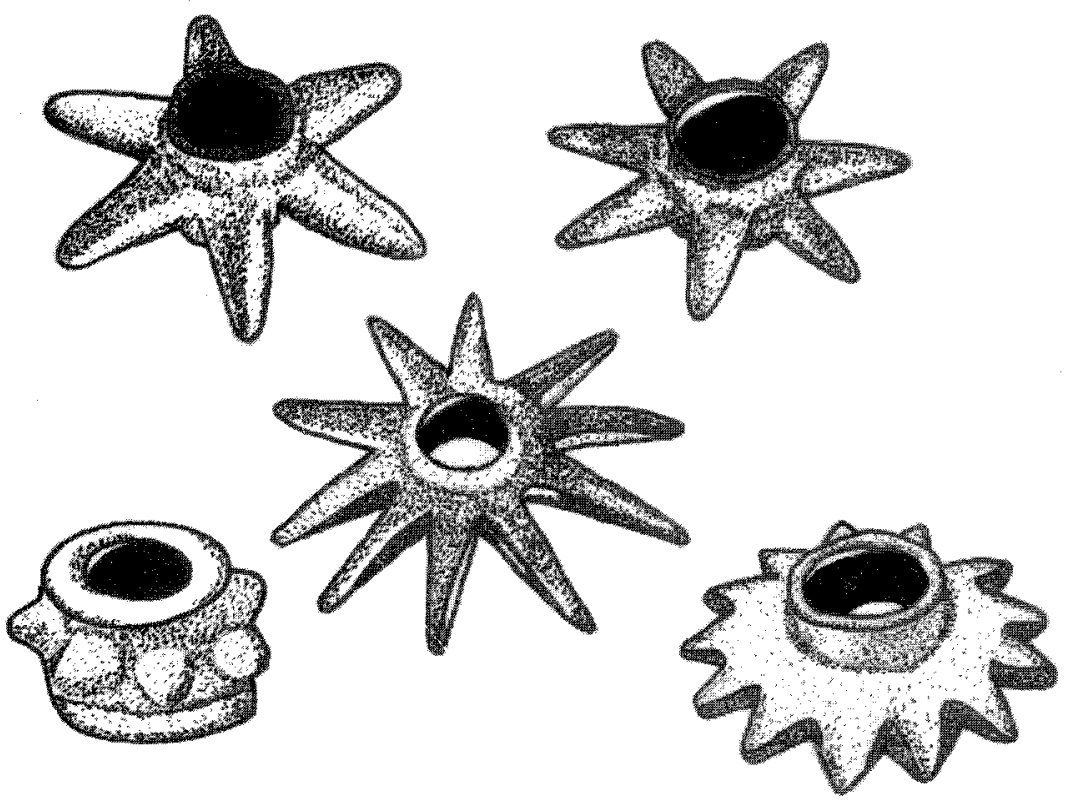

Fig. 3. Diferentes tipos de porras o mazas mochica vaciadas en cobre (de 6 a $11 \mathrm{~cm}$ ). 

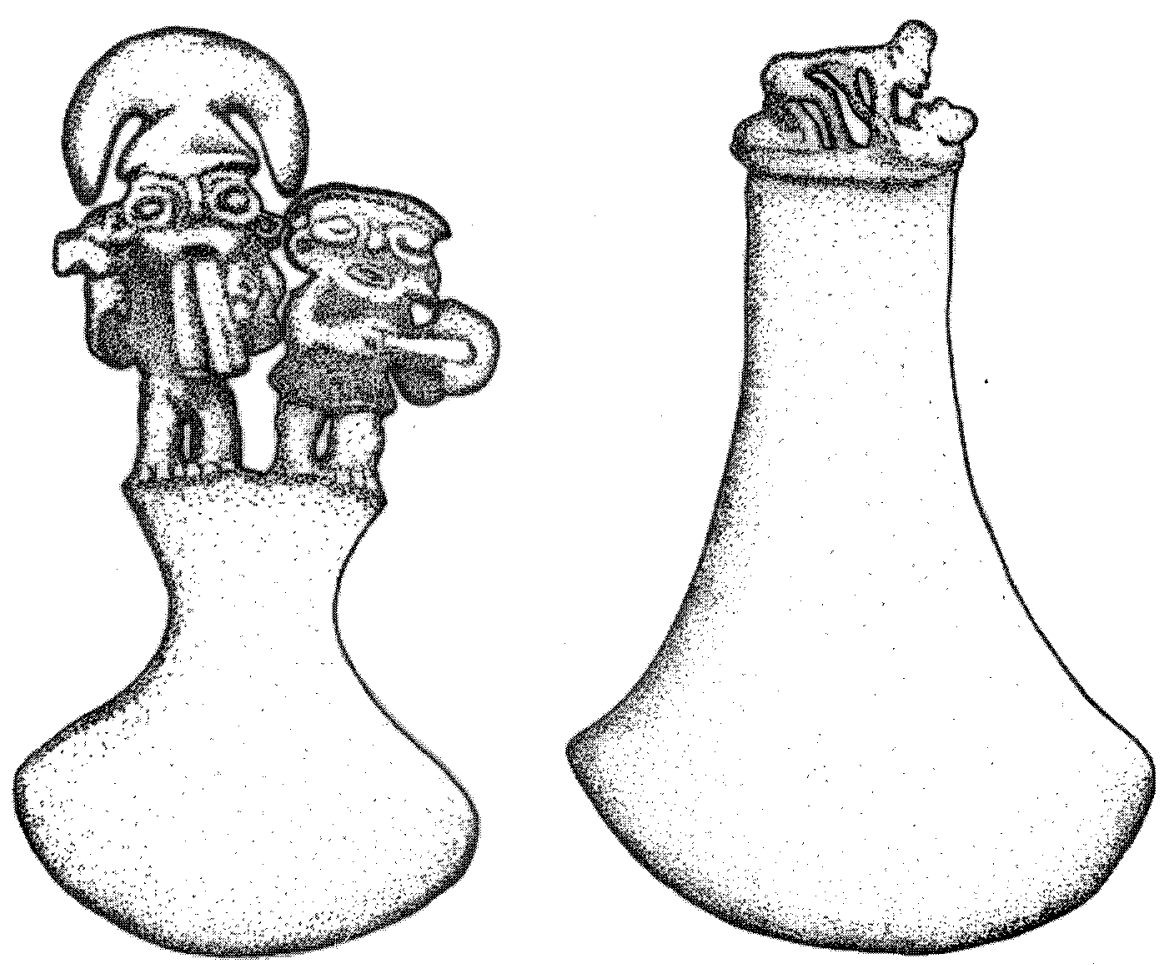

Fig. 4. Izquierda: Tumi de cobre decorado con dos músicos cazadores $(9 \times 5 \mathrm{~cm}$.). Derecha: Tumi de cobre hecho a la cera perdida con escena erótica en el mango.

en el vértice de los cascos protectores, "los golpes más eficaces se dirigían a la cabeza, ...lo que determinó el invento de estos vistosos cascos realzantes de la marcial apariencia de los soldados muchik. La forma de estos cascos se debe al armazón cónico de cañitas que tiene; cuando esta forma se creó, el mejor sitio para colocar el cuchillo fue el vértice; pero justamente por que no era arma preferida ya que exige acercarse demasiado al enemigo perdió su importancia. Probablemente los que aparecen en los dibujos no son sino regazos decorativos, y confeccionados con metales preciosos» (Muelle 1936:74). Estos complicados cascos aparecen también representados en el arte rupestre mochica.

La estólica o propulsor fue otra de las armas moche que se han encontrado realizadas de cobre. Sin embargo si una estólica no es liviana no puede cumplir eficazmente su función, (en todas las sociedades las estólicas están realizadas de madera) por lo que suponemos que estas cumplirían únicamente una función ritual. 
Entre los objetos que portan los guerreros y que vemos representados en la cerámica encontramos unos objetos que Cisneros y Lumbreras han denominado arma psicológica ya que su carácter ruidoso tuvo como objetivo causar espanto al enemigo. Se trata de una sonaja muy grande de metal que los guerreros llevaban colgada en la parte posterior del cinturón. Sólo en escenas relacionadas con la guerra aparece representado este objeto. «De cualquier manera, la gran sonaja muchik, además de servir para marcar el ritmo de las danzas, tenía una finalidad guerrera; formaba parte del atavío de los soldados. Con tal bullero aditamento, la sorpresa era difícil, pero en cambio ganaba la carga de efectividad, y ésta era la táctica preferida, la que el equipo del muchik señala. En la lucha cuerpo a cuerpo el factor sicológico es de suma importancia; el valor y la sangre fría son cualidades decisivas; el contagioso temor, que puede engendrar pánico, es la desventaja mayor; a provocarlo en el enemigo tendía el muchik, y para conseguirlo recurría a la cosmética y el atavío terroríficos, pero nada tan eficiente como el estrépito" (Muelle 1936:83).

En las tumbas reales de Sipán se encontraron varios de estos objetos: «Esta pieza fue hecha de una lámina circular de cobre dorado con 16 semiesferas repujadas y ubicadas en el borde exterior. Dentro del círculo de semiesferas dos figuras idénticas del decapitador, conectadas por la parte superior del tocado. La lámina circular fue posteriormente doblada a lo largo de esta conexión, por lo que el objeto terminó con la forma de un semicírculo. Dentro de cada esfera se puso un perdigón de cobre, con lo que se creó un sonajero con 8 componentes. Colgados de la cintura de un guerrero, estos sonajeros habrían tintineado con cualquier movimiento" (Alva 1993:39) (Fig. 5). "Cerca del hombro izquierdo del individuo había tres pares de ornamentos de cobre dorado. Estos parecen haber sido otro tipo de sonajeras en miniatura, ya que estaban hechas como la gran sonajera en forma de luna creciente» (Alva 1993:100).

En otra tumba mochica, Donnan encontró un arma muy singular con aspecto de jabalina. Se trata de un objeto alargado de madera que fue parcialmente cubierto con placas de cobre. En una de sus extremidades tenía unos huecos que permitían insertar unos travesaños de madera a los que iba atada una cuerdecilla.

La cultura Recuay se localiza en el Callejón de Huaylas, situado en la sierra Norte. No se conocen hasta el momento trabajos de metal realizados por las gentes Recuay, a excepción de pequeños objetos de cobre como los tupus (alfileres para sujetar vestimentas). Sin embargo, tanto la 


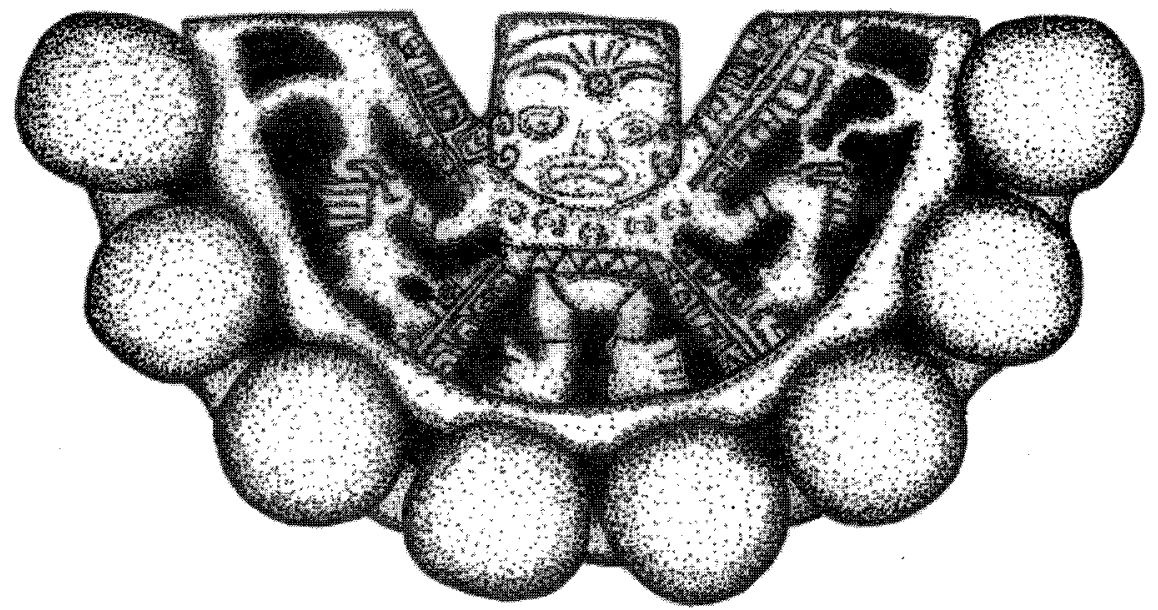

Fig. 5. Sonajero de cobre dorado encontrado en el yacimiento de Sipán.

cerámica como la litoescultura representa unos personajes denominados «Heroes-Guerreros» (Kauffmann 1977:417), los cuales portan porras, escudos y sofisticados tocados. No sabemos si éstas representaban la realidad o sólo se trata de ídolos míticos. Estas esculturas no estuvieron ligadas a ningún edificio arquitectónico tipo fortaleza, sino que parece que fueron objetos de culto emplazados en lugares estratégicos en el paisaje.

Ya en el Horizonte Medio se originó el Imperio Wari en Ayacucho que se extendió por el norte hasta la sierra de la Libertad, por la costa central hasta Supe y por el sur hasta Arequipa y Cuzco. El estudio del carácter del tamaño y distribución de los edificios Wari y sus colonias nos indica que la guerra no sólo había alcanzado un nivel de guerra ofensiva con fines de conquista, sino que se trataba ya de una institución con especialistas en la actividad bélica lo que supone por tanto la fabricación a gran escala de armas. Aunque los textiles muestran en su iconografía el uso de arcos y flechas, únicamente se han encontrado en metal gran cantidad de porras muy macizas vaciadas de cobre en forma de piñones, algunas de las cuales fueron recubiertas con un baño de oro (Fig. 6).

En el asentamiento Wari de Cerro Baúl, en Moquegua, se encontraron muchas cabezas de porra, las cuales, por su composición y tecnología parecen haber sido fabricadas por artesanos Tiwanaku.

La cultura Tiwanaku integró todo el altiplano, norte y sur, bajo una unidad política desde el 600 al 1200 d.C. en que colapsó totalmente. A 


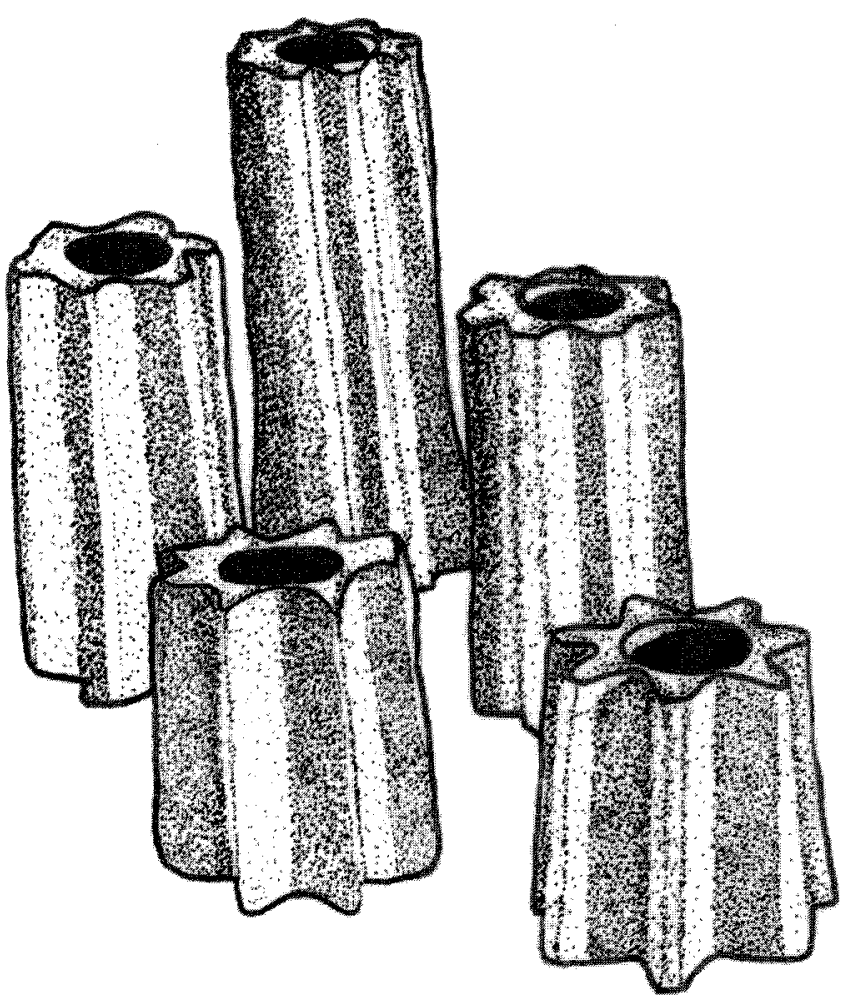

Fig. 6. Porras vaciadas en forma de piñones $( \pm 6 \mathrm{~cm}$.).

pesar de que colonizaron los valles de la vertiente oriental y occidental de los Andes de la zona sur, no se les conoce como una sociedad guerrera. Tanto en Bolivia como en el norte de Chile y en el Noroeste argentino se han encontrado hachas en forma de "T» que Mayer separara en dos categorías: "hachas-T con hoja delgada" y "hachas-T con cuerpo grueso». Fueron de bronce estañífero y arsenical y se han encontrado tanto en contextos domésticos como en tumbas. (Fig. 7) Letchman refiriéndose a los hallazgos encontrados en San Pedro de Atacama (Chile), nos dice que «estas hachas se encuentran predominantemente en tumbas con tablillas talladas de rapé, como las que están estrechamente asociadas a la religión y a la iconografía Tiwanaku del horizonte medio" (Letchman 1997:167). Escalante(1997) afirma que estas hachas cumplian la función de instrumental de trabajo en labores de construcción, para la extracción y el corte de materiales duros. 


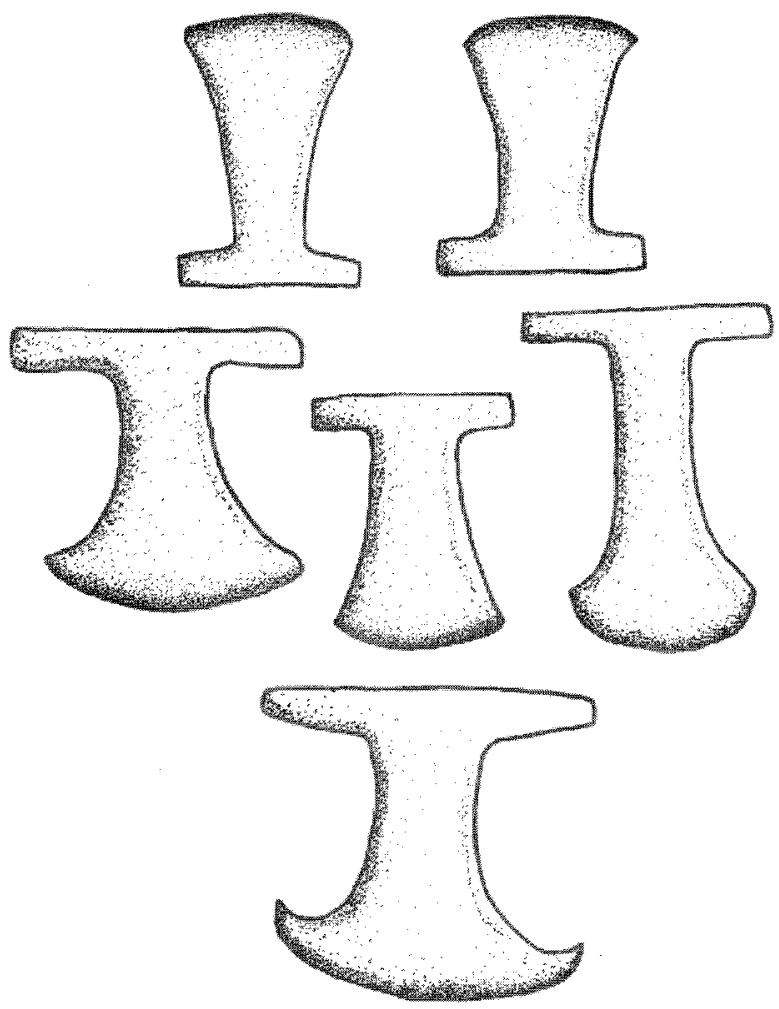

Fig. 7. Hachas-T de influencia altiplánica.

La sociedad Sicán se desarrollo en los valles de La Leche y Lambayeque en la costa septentrional. Los tesoros de oro y plata más famosos del Perú proceden indudablemente de los talleres de Sicán, en concreto, los grandes tumis de carácter ceremonial, rematados por una figura que porta un tocado en forma semicircular. En estos tumis vemos una colección de elementos notables y materiales ostentosos. Se emplean diferentes posibilidades técnicas del metal, casi como para dar una demostración; alambre angulado y torcido, enhebrado de cuentas y bordes repujados para resaltar piedras incrustadas etc... El rasgo más notable de estos tumis es la representación constante de una divinidad con el rostro rectangular y la mandíbula curva y redondeada, con los ojos en forma de coma con las comisuras externas puntiagudas, con orejas rectangulares con orejeras grandes circulares y con un complicado tocado en forma de media luna. (Fig. 8). Culturalmente estos tumis de oro eran prerrogativas 


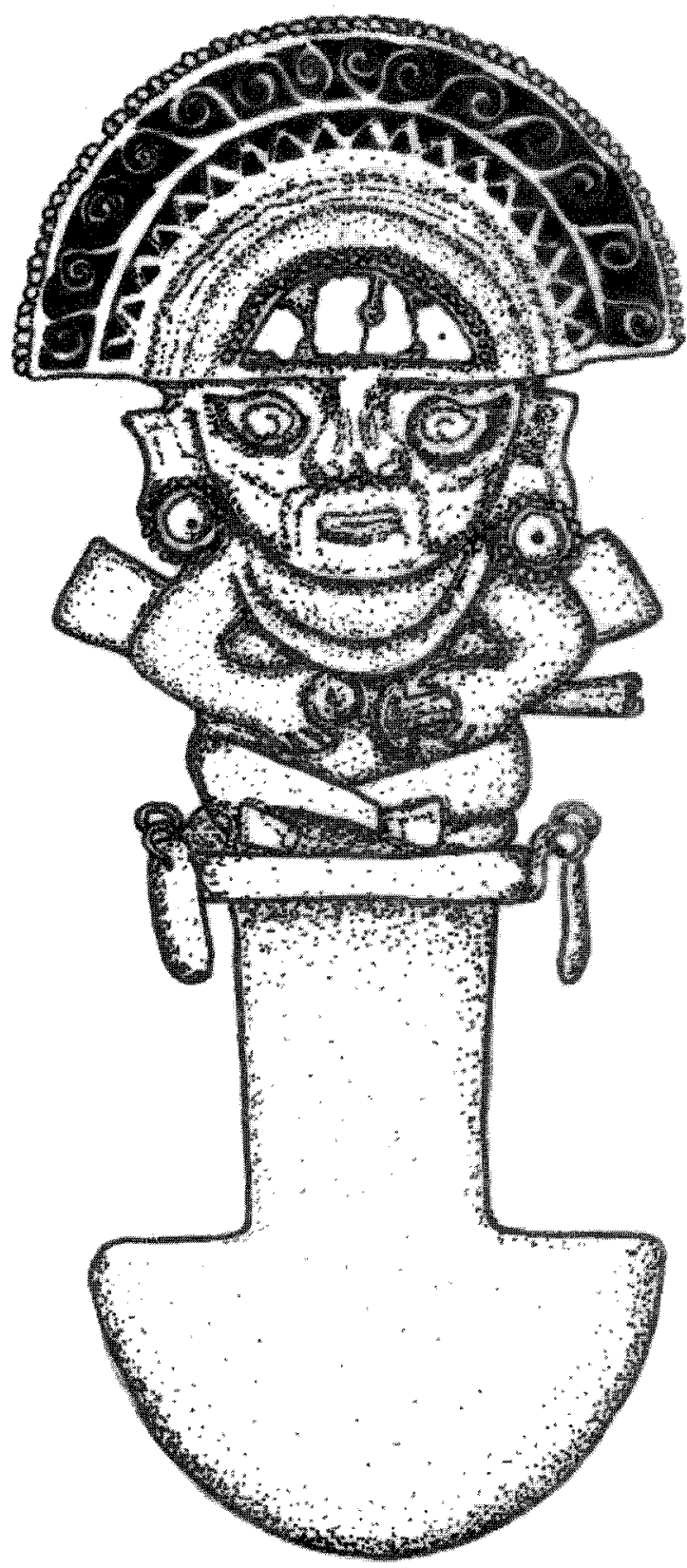

Fig. 8. Tumi de oro y crisocola Sicán. 
de las élites gobernantes y su uso principal se daba en contextos funerarios. «En las tumbas de Sican se han encontrado tumis de cobre por centenares en los ajuares funerarios. Normalmente son bronces arsenicales formados sólo por el brazo vertical y la semicircunferencia sin representación de figura alguna. Estos varian mucho en tamaño y se hallan formando paquetes de docenas, a veces formando atados con cuerdas de algodón o envueltos en telas sin huellas de aparente uso." (Carcedo 1999:216).

El llamado Reino Chimú ocupó un área muy limitada de la costa norte que, por el norte se extiende hasta Piura y por el sur hasta Huarmey, durante los años 1100 al 1470 d.C. Hay miles de objetos de metal supuestamente chimús en colecciones de todo el mundo, pero su procedencia es vaga y sus atribuciones dudosas. Encontramos tumis realizados en cobre mediante vaciado en moldes o mediante la técnica de cera perdida, tan sofisticados que no podrían imaginarse como parte de la parafernalia militar. Lechtman nos comenta como entre los artefactos norteños de bronce arsenical por lo menos entre los valles de Moche y Lambayeque, en el período Intermedio Tardío, existen puntas de lanza que junto a implementos agrícolas fueron encontrados por centenares en tumbas Chimú Medio. Asegura que tanto las puntas de lanza como el resto de los implementos no cumplen una función utilitaria, es decir ni las puntas sirvieron para la guerra o la caza, ni las herramientas agrícolas para ser utilizadas en el campo, si no que "parecen ser depósitos o concentraciones de metal. Parece evidente, por su peso, por haber sido enterrados en gran número, por el burdo acabado de algunos, por la apariencia de lingotes de otros, que en sí el bronce era considerado valioso y como tal acumulado" (Lechtman 1978:508).

El Tahuantinsuyo o imperio de los Incas duró apenas un siglo, sin embargo su expansión territorial fue la mayor hasta la llegada de los españoles. El armamento incaico, así como otros muchos aspectos de su cultura, fueron ampliamente descritos y representados por los cronistas del siglo XVI. Huamán Poma de Ayala dibujó innumerables escenas de la vida cotidiana, la guerra, la realeza, los rituales en definitiva de todas las manifestaciones culturales incaicas. Cieza de León nos dice «...en los depósitos habia grandisima cantidad de oro en tejuelos y de plata en pasta...En fin sus atambores y asentamientos y estrumentos de música y armas para ellos eran deste metal» (Cieza de León 1967:44). «Y cada capitania llevaba su bandera y unos eran onderos y otros lanceros y otros peleaban con macanas y otros con ayllos y dardos y algunos con porras» (Cieza de León 1967:81). Fray Bartolomé de las Casas también hace referencia a las armas en sus textos diciendo: «...y peleaban con porras 
que traian ceñidas y eran de piedras horadadas y otras de metal o cobre a manera de estrella con astil que les pasaba por medio de cuatro palmos" (Carcedo 1999: 526), así como el Inca Garcilaso de la Vega, «...por ultima dibisa real davan al principe un hacha de armas que llamaban Champi, con un asta de mas de una braza en largo. El hierro tenia una cuchilla de la una parte y una punta de diamante de la otra, que para ser partesana no le faltaba mas que una punta» (Carcedo 1999:526).

Los queros son vasos de madera en cuyas superficies se representaron escenas de acontecimientos y las representaciones de escenas bélicas también están presentes.

Las estólicas eran de madera, las hondas o huaracas de cuero o lana de camélido, las lanzas o chuquis de madera muy dura y las boleadoras, lihuis o ayllus de piedra, sin embargo, encontramos también entre los implementos ofensivos bélicos objetos de metal, como las porras o macanas que fueron realizadas en piedra o en metal, sujetas a un mango de madera, las lanzas con puntas de madera o de metal y las hachas de combate. Los incas sin embargo no inventaron nada sino que éstas ya venían formando parte del bagaje cultural de las sociedades preincaicas. La mena de estaño procedente del sur del lago Titicaca, se transportaba a todos los puntos del imperio inca para ser mezclado con el cobre local, es así como el bronce con estaño.

Las porras o «rompecabezas» como así las llamaron los españoles fueron realizadas mayormente de cobre, vaciadas y con formas preferentemente estrelladas de cinco o seis puntas, y con unas dimensiones que no superan generalmente los $15 \mathrm{~cm}$. Existen porras atípicas en las que una de las puntas de estrella ha sido sustituida por una pequeña hacha que supuestamente tuvo el fin de ser asi más efectiva. Todas ellas iban enmangadas a un grueso palo de madera. Las hachas o "champis" (Espinoza 1990: 373) también fueron realizadas en cobre vaciadas. Las hachas-piquete están conformadas por una punta gruesa y larga de metal que se enmangaba perpendicularmente a un palo de madera. (Fig. 9). Este tipo de hacha, que evidentemente tuvo una función bélica, ha sido encontrada como ofrenda funeraria en enterramientos de la pacífica sociedad Chiribaya, localizada en el departamento de Ilo, en la costa Sur. Los Chiribaya obtendrían estos objetos por medio de intercambios con los Incas y supondrían un bien muy preciado, digno de formar parte del ajuar funerario de personajes de élite (Gerardo Carpio, comunicación personal). Las hachas en forma de "T» fabricadas por los metalurgos incaicos tienen una influencia tiwanacota Son muy macizas y algunas presentan diseños geométricos cincelados. Los Chincha, cultura local desarrollada en el valle 


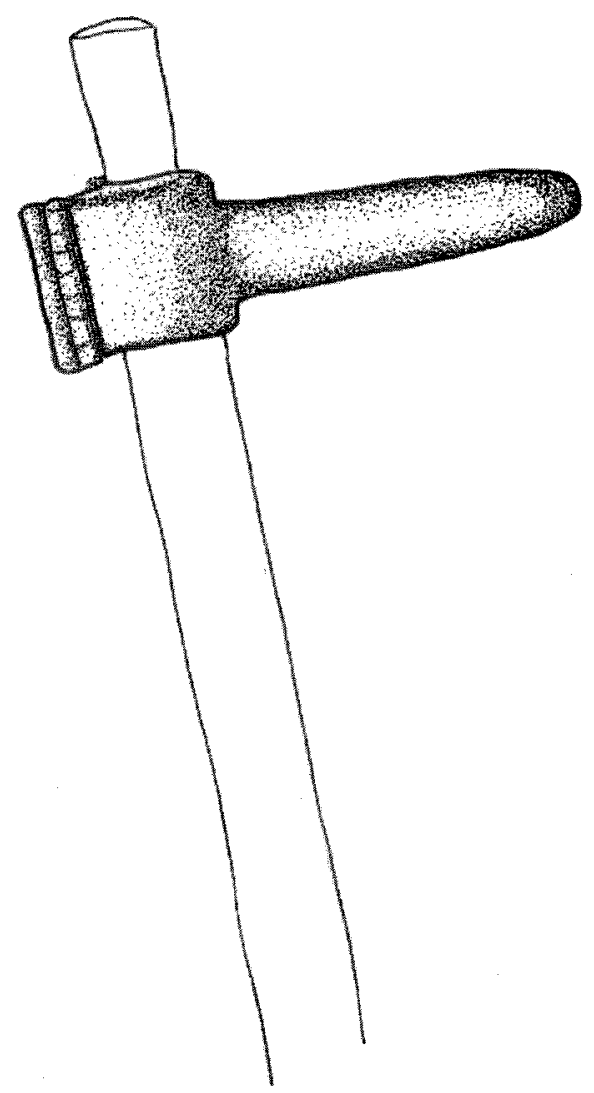

Fig. 9. Hacha-piquete enmangada a un palo de madera.

del mismo nombre y que convivió con los incas, fabricaron este tipo de hacha en forma de «T» por centenares. Estas han sido encontradas en cantidad en contextos funerarios del Ecuador. En esta época existió un comercio muy activo entre las costas de Ecuador y Perú y los Chincha intercambiaban las hachas por Spondylus, textiles etc. Se las ha denominado hachas moneda y se ha desvinculado la función como armas de las mismas, ya que se encuentran estandarizadas en forma y algunas de ellas sobrepasan su peso $(20 \mathrm{~kg}$.) para ser utilizadas como tales. Definitivamente fue posible la existencia de acumulación de riqueza a través de la tenencia de estas "hachas-moneda» así como la existencia de un sistema de intercambio de éstas a gran escala. Otros tipos de hachas incaicas son aquellas que tienen su hoja en forma de media luna y de hoz, y que fueron martilladas en el filo (Fig. 10). 

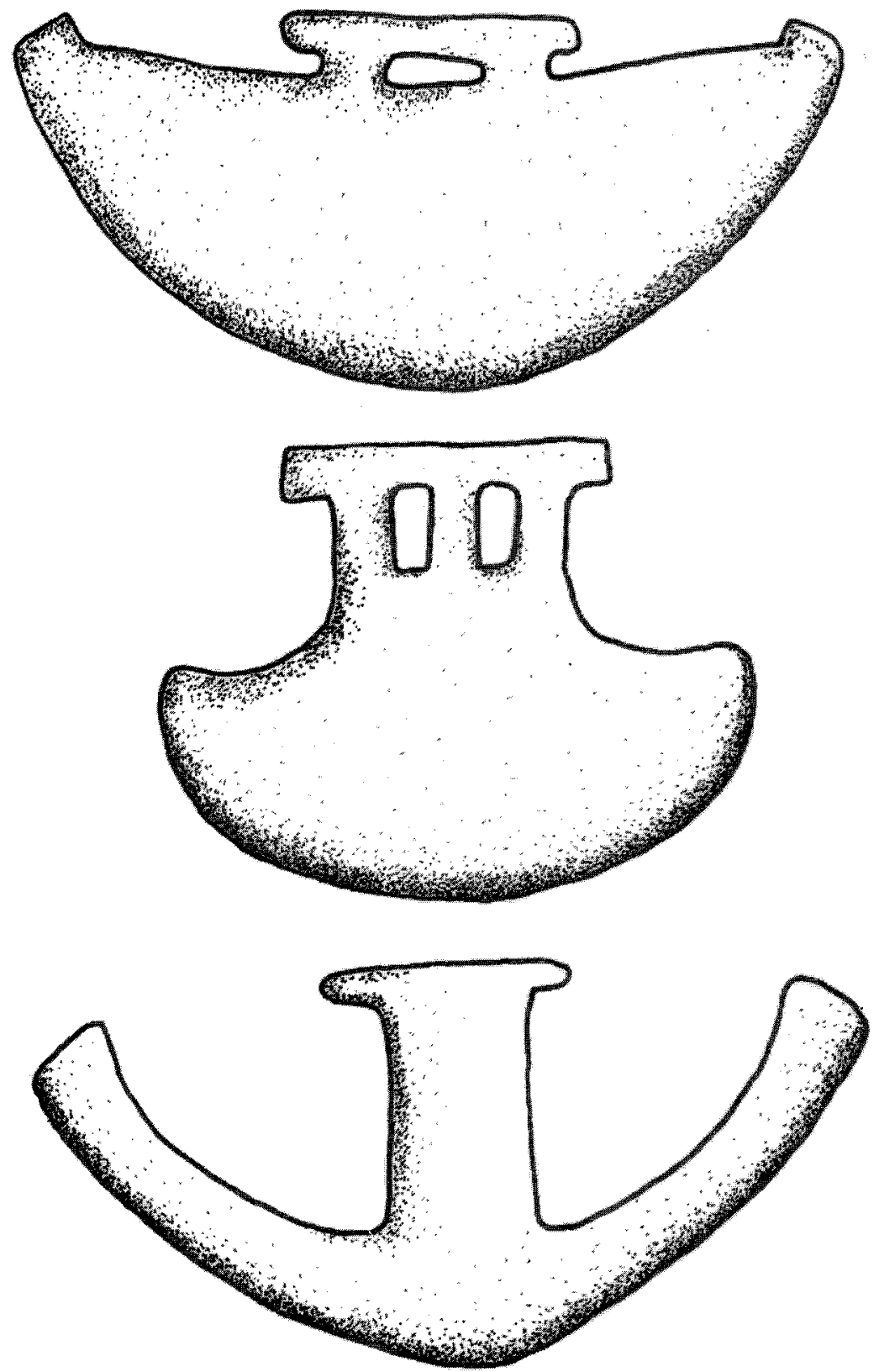

Fig. 10. Hojas de hachas semicirculares martilladas en el filo $(12 \times 27.5 \mathrm{~cm}$ y $17.5 \times 10.2 \mathrm{~cm}$.) $y$ hacha vaciada con hoja hoz. $(17.5 \times 10.2 \mathrm{~cm}$.). 
Sólo hemos encontrado un ejemplo de un tipo de arma que Carcedo denomina manopla (Fig. 11).
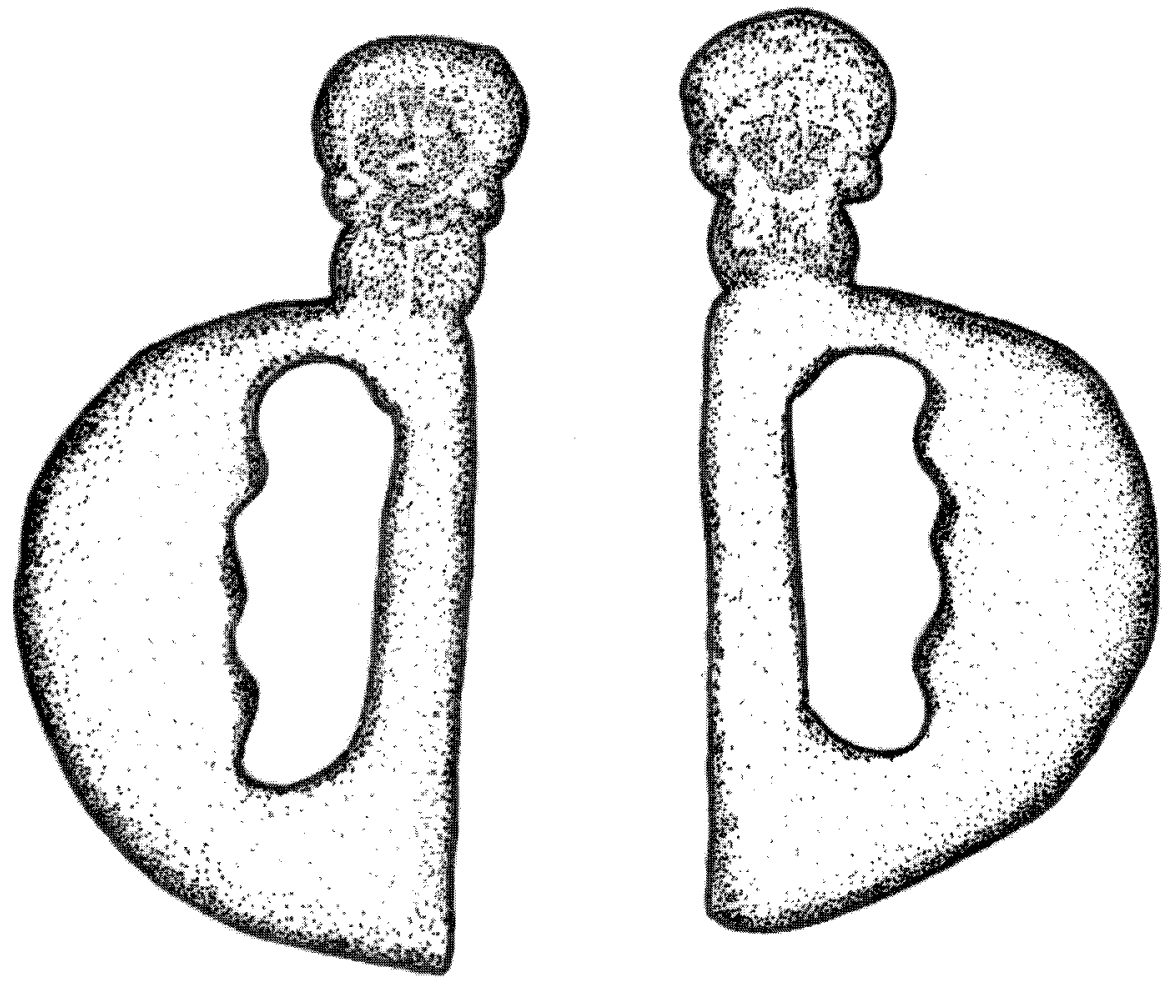

Fig. 11. «Manoplas» vaciadas de cobre.

Los tumis inca parece que cumplieron exclusivamente una función ritual aunque también hay autores que afirman que sirvieron para la trepanación de cráneos en operaciones quirúrgicas (Espinoza 1990). Presentan una particularidad: "Se funden a partir de cobre o plata, dejando huecos o ranuras para introducir la incrustación; luego se cortaban trozos de otros metales hasta darles la forma deseada, se les embutía o pegaba. A veces, para rellenar los huecos se utilizaba pasta coloreada en lugar de metal.» (Bray 1991:75). En la parte superior de los mismos se representan animales cuadrúpedos (camélidos, felinos, venados o monos) (Fig. 12). 

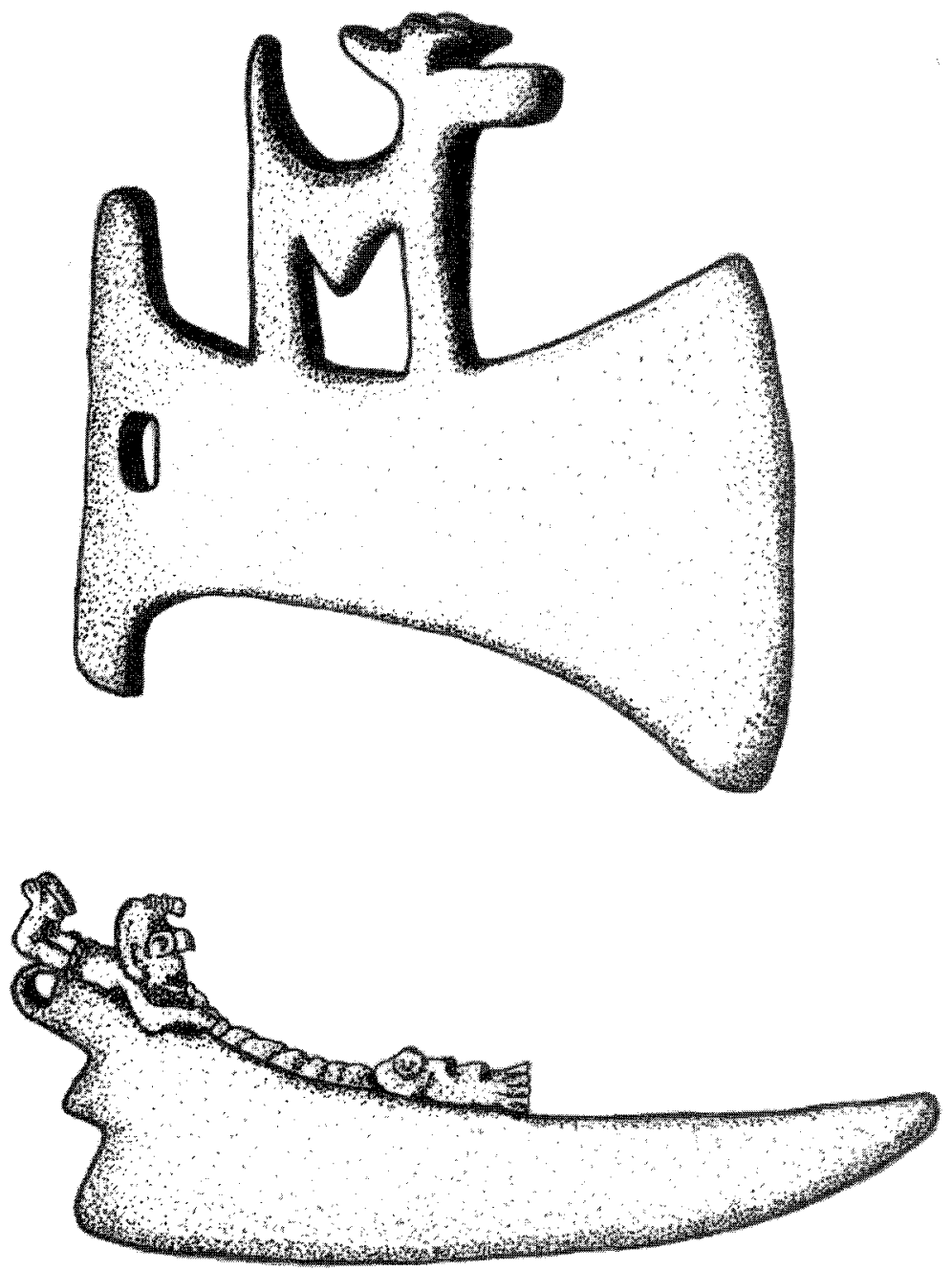

Fig. 12. Hacha-T con venado estilizado $(8 \times 4 \mathrm{~cm}$.) y cuchillo decorado con escena en el mango.

(Las ilustraciones han sido realizadas a partir de fotografías editadas en las siguientes publicaciones:

Figs. 1 y 5: Alva W y C. Donnan. Las tumbas reales de Sipán. Universidad de California. Los Angeles.1993.

Figs. 2, 3, 4, 6, 7, 9, 10, 11, 12 (sólo el hacha-T): Carcedo P. El cobre del Antiguo Perú. Lavalle ed. Lima. 1999.

Figs.8 y 12 (sólo el cuchillo): Kauffman-Doig F. Historia de los peruanos. Peisa. Lima.1977. 

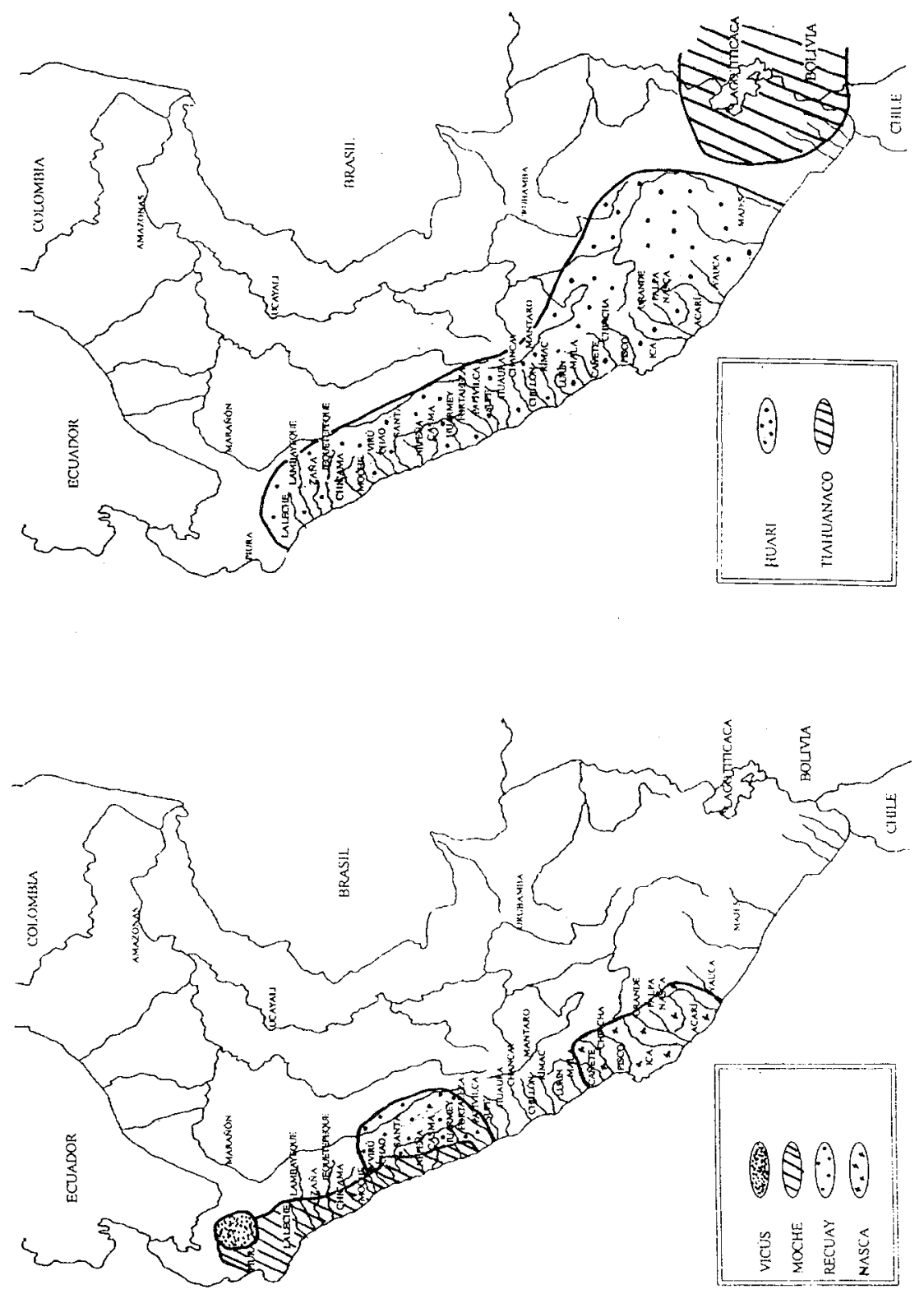

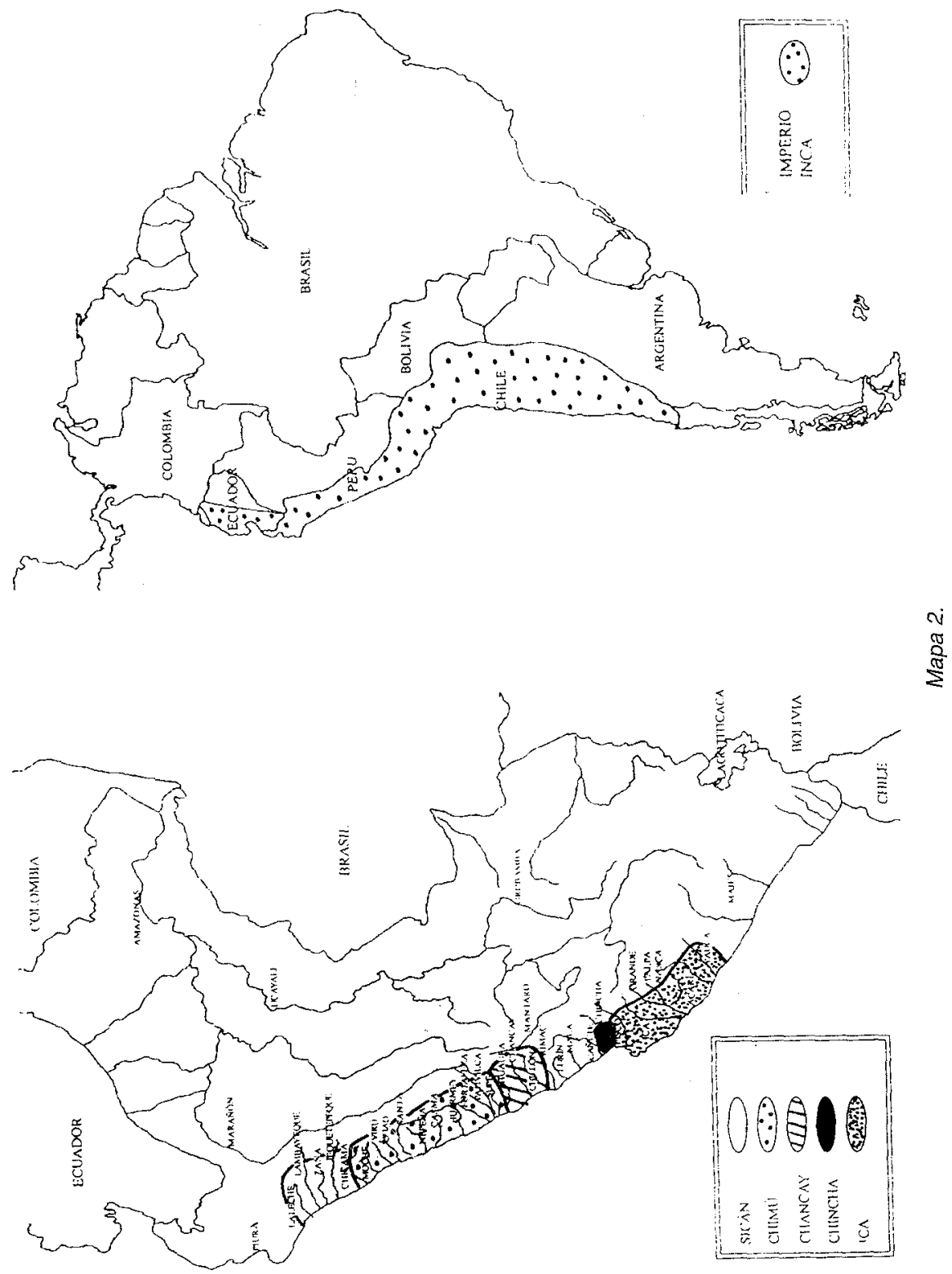


\section{CUADRO RESUMEN}

\begin{tabular}{|c|c|c|c|c|}
\hline CRONOLOGÍA & $\begin{array}{l}\text { HORIZONTES } \\
\text { CULTURALES }\end{array}$ & CULTURAS & TIPOS DE ARMAS & SOPORTE MATERIAL \\
\hline 1532 d.C. & Horizonte Tardio & Inka & $\begin{array}{l}\text { Tumis } \\
\text { Hachas } \\
\text { Porras } \\
\text { Manoplas }\end{array}$ & $\begin{array}{l}\text { Cobre-estaño (bronce estañífero) } \\
\text { Cobre } \\
\text { Cobre-estaño }\end{array}$ \\
\hline 1450 d.C. & Intermedio Tardio & $\begin{array}{l}\text { Chimú } \\
\text { Lambayeque } \\
\text { Chancay } \\
\text { Chincha } \\
\text { Chiribaya }\end{array}$ & $\begin{array}{l}\text { Tumis } \\
\text { Hachas } \\
\text { Porras }\end{array}$ & $\begin{array}{l}\text { Oro, plata, cobre } \\
\text { Cobre-arsénico (bronce arsenical } \\
\text { Cobre } \\
\text { Cobre-arsénico (bronce arsenical }\end{array}$ \\
\hline \pm 900 d.C. & Horizonte Medio & $\begin{array}{l}\text { Wari } \\
\text { Tiwanaku }\end{array}$ & $\begin{array}{l}\text { Hachas } \\
\text { Porras }\end{array}$ & $\begin{array}{l}\text { Cobre } \\
\text { Cobre-arsénico (bronce arsenical } \\
\text { Cobre-estaño (bronce estañifero) }\end{array}$ \\
\hline \pm 600 a.C. & $\begin{array}{l}\text { Intermedio } \\
\text { Temprano }\end{array}$ & $\begin{array}{l}\text { Moche } \\
\text { Recuay } \\
\text { Nazca }\end{array}$ & $\begin{array}{l}\text { Tumis, hachas, porras } \\
\text { Porras, puntas de flecha } \\
\text { Estólicas, p. de flecha }\end{array}$ & $\begin{array}{l}\text { Oro, plata, cobre, cobre-arsénico } \\
\text { Piedra y metal?, pizarra } \\
\text { Madera, obsidiana }\end{array}$ \\
\hline \pm 1500 a.C. & $\begin{array}{l}\text { Horizonte Antiguo } \\
\text { o Formativo }\end{array}$ & & $\begin{array}{l}\text { Porras } \\
\text { Estólicas } \\
\text { Puntas de flecha } \\
\text { Boleadoras }\end{array}$ & $\begin{array}{l}\text { Piedra } \\
\text { Madera } \\
\text { Piedra } \\
\text { Piedra y cuero }\end{array}$ \\
\hline \pm 2000 a.C. $\downarrow$ & Precerámico $\downarrow$ & & $\begin{array}{l}\text { Boleadoras Arco } \\
\text { y flechas }\end{array}$ & $\begin{array}{l}\text { Piedra y cuero } \\
\text { Madera y cuero, piedra }\end{array}$ \\
\hline
\end{tabular}

\section{BIBLIOGRAFIA}

Alva, W. y Donnan, C. (1998): Las tumbas reales de Sipán. Universidad de California. Los Angeles. BENNET, W. y BIRD, J. (1960): Andean Culture History. American Museum of Natural History. Nueva York.

Bray, W. (1991): «La metalurgia en el Perú Prehispánico» en Los Incas y el Antiguo Perú. Quinto Centenario. Madrid.

CARCEdo, P. (1999): El cobre del Antiguo Perú. Lavalle ed. Lima.

- El trabajo del metal en los Andes Centrales. (En prensa).

CIEZA DE LEón, (1967): El Señorio de los Inkas. IEP, Lima.

CISNeROS, L. y LumBreras, L. (1980): Historia general del ejército peruano. Los orígenes. Ministerio de Guerra. Lima.

Escalante, J. (1997): Arquitectura prehispánica en los Andes Bolivianos. Ed. Cima. La Paz.

ESPINOZA, W. (1990): Los Incas. Economía, sociedad y estado en la era del Tahuantinsuyo. Amaru editores. Lima.

HOEBEL (1961): El hombre en el mundo primitivo. Omega S.A. Barcelona.

Kauffmann-Dolg, F. (1977): Historia de los peruanos. Peisa. Lima.

LECHTMAN, H. (1978): «Temas de metalurgia andina», en Tecnología andina. I.E.P. Lima.

- (1997): «El bronce arsenical y el Horizonte Medio», en Arqueología, antropología e historia. Homenaje a María Rostwrowski. I.E.P. Lima. 1997. 
LOTHROP (1978): "Instrumentos para trabajar metales de la Costa Central de Perú», en Tecnología andina. I.E.P. Lima.

MAKOWSKI, K. (1996): «Taller de Yécala (s.III-IV d.C.): observaciones sobre las características y organización de la producción Vicús, en Boletín Museo del Oro 41. Lima. - (1999): «La guerra ritual», en El Dorado. Promperú. Lima.

Muelle, J. (1936): "Chalchaca. Un análisis de los dibujos muchik», en Revista del Museo Nacional. Tomo V-I Lima.

RAvines, R. (1978): Tecnología andina. Instituto de Estudios Peruanos. Lima.

TOPIC, J. y LANGE TOPIC, T. (1997): «Hacia una comprensión conceptual de la guerra andina", en Arqueología, antropología e historia en los Andes. Homenaje a María Rostworowski. I.E.P. Lima. 